\title{
Sepsis by Capnocytophaga
}

\author{
Lara Ines Bellazzi, ${ }^{1}$ Liudmyla Diachyshyna, ${ }^{2}$ Marcella Mercuri, ${ }^{2}$ Cristina Terulla, ${ }^{1}$ Panajota Troupioti, ${ }^{1}$ \\ Filippo Costanzo ${ }^{3}$ \\ ${ }^{1}$ Laboratorio di Analisi, Ospedale di Voghera, ASST Pavia; ${ }^{2}$ Scuola di Specializzazione in Microbiologia e Virologia, \\ Università degli Studi di Milano; ${ }^{3}$ Dipartimento di Medicina Interna, Ospedale di Voghera, ASST Pavia, Italy
}

\section{Summary}

Capnocytophaga species is a commensal gram-negative rod capnophilic facultative anaerobic bacterium that colonizes the oral cavity of humans and animals. This bacterium can cause severe illness in patients with alcohol addiction, chronic lung diseases, liver diseases and immunosuppression. Herein, we report a rare case of sepsis caused by $C$. sputigena in a 83-year-old woman.

\section{Introduction}

Capnocytophaga species is a commensal gram-negative rod capnophilic facultative anaerobic bacterium that colonizes the oral cavity of humans ( $C$. sputigena and $C$. gengivalis) and animals such as dogs and cats (C. canimorsus). This bacterium can cause severe illness in patients with alcohol addiction, chronic lung diseases, liver diseases and immunosuppression. Capnocytophaga spp. have been recovered from subgingival plaque, dental pockets, tracheal secretions, bronchoscopy specimens, aspirates of wounds, abscesses and blood. The human species are implicated in periodontal disease and in systemic infections while $C$. canimorsus is responsible for infectious complications of animal bites (3).

Correspondence: Lara Ines Bellazzi, Laboratorio di Analisi, Ospedale di Voghera, Via Volturno, 14, 27058 Voghera, Italy.

E-mail: laraines.bellazzi@gmail.com

Key words: Capnocytophaga, sepsis.

Contributions: the authors contributed equally.

Conflict of interest: the authors declare no potential conflict of interest.

Received for publication: 27 September 2017.

Revision received: 15 December 2017.

Accepted for publication: 19 December 2017.

CC Copyright L.I. Bellazzi et al., 2017

Licensee PAGEPress, Italy

Microbiologia Medica 2017; 32:7105

doi:10.4081/mm.2017.7105

This article is distributed under the terms of the Creative Commons Attribution Noncommercial License (by-nc 4.0) which permits any noncommercial use, distribution, and reproduction in any medium, provided the original author(s) and source are credited.
Capnocytophaga spp. are usually susceptible to extendedspectrum cephalosporins, carbapenems, fluoroquinolones, chloramphenicol, clindamycin, erythromycin and are resistant to aztreonam, aminoglycosides, trimethoprim and metronidazole (3).

In this clinical case, we report a rare case of sepsis caused by C. sputigena in a 83-year-old woman.

\section{Case Report}

A 83-year-old woman was admitted to our Emergency Department. The patient had fever $\left(38.2^{\circ} \mathrm{C}\right)$ but with normal blood pressure and peripheral saturation of $\mathrm{O} 2$. Chest X-ray was negative for bronchopneumonia and there weren't signs of infection of urinary and biliary tract.

She had severe oropharyngeal mucositis and different comorbidities (chronic atrial fibrillation, rheumatoid arthritis, chronic obstructive arterial disease and recent percutaneous transluminal angioplasty). The therapy taken by the patient was: methotrexate, prednisone, telmisartan, pentoxyfilline, allopurinol, calcium levofolinate, cholecalciferol, triazolam, furosemide, pantoprazole, clopidogrel, tapentadol, erythropoietin, calcine heparine.

Laboratory tests showed severe pancytopenia, acute renal failure with electrolytic disorders, high elevation of C-Reactive Protein (PCR) and procalcitonine (leukocytes $70 \times 10^{9} / \mathrm{L}$ with $0 \%$ of neutrophils, platelets $13 \times 10^{9} / \mathrm{L}$, hemoglobin $7.8 \mathrm{~g} / \mathrm{dL}$, creatinine $2.46 \mathrm{mg} / \mathrm{dL}, \mathrm{Na}^{+} 127 \mathrm{mEq} / \mathrm{L}, \mathrm{K}^{+} 4,56 \mathrm{mEq} / \mathrm{L}, \mathrm{Ca}^{++} 8.14$ $\mathrm{mg} / \mathrm{dL}$, PCR $34.31 \mathrm{mg} / \mathrm{dL}$ and procalcitonin $7.27 \mathrm{ng} / \mathrm{mL}$ ). Sequential Organ Failure Assessment score (SOFA) was 7.

The patient was hospitalized with the suspect of sepsis in severe neutropenia.

Therefore two sets of blood cultures were performed and the patient began immediately empirical support antibiotic therapy with imipenem, vancomycin and fluconazole. The patient was given transfusion support (erythrocytes and platelets) and granulocyte growth factors (Filgrastim $0.5 \mathrm{~mL} / \mathrm{die}$ ). Despite early treatment, there was a progressive clinical deterioration with exitus in the third day of hospitalization. Subsequently, in the blood cultures we isolated $C$. sputigena sensible at imipenem.

Two sets of blood cultures were collected from the patient at the admission and sent to the laboratory. Blood was cultured in 2 BACTEC Plus/F Aerobic and 2 BACTEC Plus/F anaerobes; the samples were incubated in BD BACTEC 9120System. The positive bottles were seeded on Blood and MacConkey agar and incubated in $10 \% \mathrm{CO} 2$ at $37^{\circ} \mathrm{C}$ overnight. The positive samples were subjected to Gram-staining. Other biochemical tests used for identification were catalase test and oxidase test.

The final identification of the bacterium was obtained by means of mass spectrometry MALDI-TOF (Bruker Daltonics) and 
antibiotic susceptibility testing was obtained with BD Phoenix Automated Microbiology System.

\section{Results}

Blood cultures resulted positive after 2 days of incubation in BD BACTEC 9120System. Tiny non-hemolytic colonies of Gramnegative bacilli appeared on $10 \%$ sheep blood agar after 2 days of incubation in $10 \% \mathrm{CO} 2$ at $37^{\circ} \mathrm{C}$. The colonies were convex or flat with irregular edges, with spreading growth and pitting of the agar observed. On MacConkey agar there was no growth.

The microscopical examination of the Gram slide showed the presence of Gram-negative rods morphologically similar to fusobacteria $(4,5)$. The catalase and oxidase test were negative. The biochemical reactions allowed to differentiate between $C$. sputigena (negative catalase; negative oxidase) and C. canimorsus (positive catalase; positive catalase) (4). Finally, the species $C$. sputigena was identified by means of mass spectrometry MALDITOF (Bruker Daltonics).

\section{Discussion and Conclusions}

We have selected the presentation of this clinical case because there are few cases of sepsis caused by this bacterium. We have hypothesized that the septicemia is hypothetically started from the mouth of the patient. In fact, the patient had severe oropharyngeal mucositis and $C$. sputigena is commonly found in the human oral cavity as part of the normal gingival flora (6). Furthermore, this case is an example of how in frail and aged subjects there is a greater predisposition for infection caused by saprophytic germs. The risk for infection is further increased by host factors, invasive procedures and excessive polypharmacological therapy that may be causes of severe complications, sometimes fatal $(1,2)$.

\section{References}

1. Del Bono V, Giacobbe DR. Bloodstream infections in internal medicine. Virulence 2016;7:353-65.

2. Heppner HJ, Cornel S, Peter W, et al. Infections in the elderly. Crit Care Clin 2013;29:757-74.

3. Innocenti P, Aschbacher R, Ladinser B, et al. Capnocytophaga canimorsus sepsis: two clinical cases at the Bolzano Regional Hospital. Microbiol Med 2010;25:270-1.

4. Murray PR, ed. Manual of Clinical Microbiology. Washington DC: American Society for Microbiology 2005.

5. Ohler RL, Velez AP, Mizrachi, et al. Bite related and septic syndromes caused by cats and dogs. Lancet Infect Dis 2009;9:439-47.

6. Ooshima T, Nishiyama N, Hou B, et al. Occurence of periodontal bacteria in healthy children: a 2-year longitudinal study. Commun Dent Oral Epidemiol 2003;31:417-25. 